\title{
A FÊNIX TUPINIQUIM: AS (RE)INVENÇÕES DA POLÍCIA MILITAR (1809-1936)
}

\author{
SAMUEL ROBES LOUREIRO
}

Doutor e Mestre em Educação pela PUC/SP, Mestre Profissional pelo CAES-PMESP. Possui bacharelado e Licenciatura em História pela USP e bacharelado em Ciências Policiais de Segurança e Ordem Pública pela APMBB. Tenente-coronel da reserva da PMESP. Atualmente é professor na Faculdade de Educação da USP.

País: Brasil Estado: São Paulo Cidade: Praia Grande

Email de contato: samuel.loureiro@usp.br ORCID: http://orcid.org/0000-0001-9998-334X

\section{RESUMO}

Tendo como tema a história das Polícias Militares (PMs) brasileiras, a partir do estudo das ligações entre a história do Exército, da Polícia Militar do Estado do Rio de Janeiro (PMERJ) e da Polícia Militar do Estado de São Paulo (PMESP), buscamos demonstrar o processo histórico de vinculação legal entre as PMs e o Exército. O estudo faz uso da noção de processos históricos de Thompson e da ideia de longa duração de Braudel. Para tal, foram analisados diversos tipos de fontes que evidenciaram o processo histórico de formação dessas corporações, suas imbricações com a história do Exército e as permanências e mudanças ao longo dos anos. O artigo conclui que as corporações criadas no século XIX para o serviço de policiamento na Corte e na cidade de São Paulo, marcadas por atuações truculentas, após a Revolução de 1930, aliaram-se a alguns oficiais do Exército e, como uma espécie de fênix, reinventaram-se visando sobreviver à extinção iminente. Com isso, durante a Era Vargas, transformaram-se em um novo tipo de corporação: a Polícia Militar, força reserva e auxiliar do Exército. Este resultado demonstrou como determinadas instituições sobrevivem ao processo histórico, por meio de mecanismos como a adaptação e a reinvenção.

Palavras-chave: História das instituições. Segurança pública. Polícia Militar. Exército.

\section{ABSTRACT \\ THE TUPINIQUIM PHOENIX: THE (RE)INVENTIONS OF THE MILITARY POLICE (1809-1936)}

Considering the history of the Brazilian Military Police and starting from a study of the connections between the history of the Army, the Military Police of the State of Rio de Janeiro (PMERJ) and the Military Police of the State of São Paulo (PMESP), we seek to demonstrate the historical process of legal attachment between the PMs and the Army. The study makes use of Thompson's notion of historical processes and Braudel's idea of long duration. The analysis of several different types of source material have provided evidence for the historical process of the founding of these corporations, the ways in which these are interwoven with the story of the Army, and continuities and changes that have occurred over the years. The article concludes that the corporations created in the 19th Century in order to serve the policing needs of the court and the city of São Paulo were marked by truculent actions. After the Revolution of 1930, they aligned with some Army officials and, like a phoenix, reinvented themselves in order to survive eminent extinction. With this, during the Vargas' age they transformed into a new type of corporation: the Military Police, reserve and auxiliary force of the Army. This 
result demonstrates how determined institutions survive historical processes by way of mechanisms such as adaptations and reinvention.

Keywords: The History of institutions. Public security. Military Police Force. Army.

DOI: $10.31060 /$ rbsp.2021.v15.n1.1198

Data de recebimento: 19/08/2019 - Data de aprovação: 09/06/2020

\section{INTRODUÇÃO}

O presente artigo tem como tema a história das Polícias Militares (PMs) brasileiras, e como objeto a imbricação entre as histórias da Polícia Militar do Estado do Rio de Janeiro (PMERJ), da Polícia Militar do Estado de São Paulo (PMESP) e do Exército. A escolha dessas corporações tem ligação com o processo de atrelamento legal entre as PMs e o Exército ocorrido, como veremos mais adiante, em tempos históricos diferentes para a PMERJ e para a PMESP, o que ajuda a compreender os processos de gênese e consolidação da ideia de Polícia Militar no Brasil a partir de um modelo de PM que já surge vinculada ao Exército, como é o caso da PMERJ, e outro que surge como fruto do processo de descentralização das forças militares brasileiras ocorrido no final do séc. XIX, grupo representado pela então Força Pública do Estado de São Paulo (FPESP) ${ }^{1}$, maior corporação militar estadual do Brasil nas primeiras décadas do séc. XX.

A partir dessa análise, o presente artigo tem por objetivos discutir a vinculação legal entre as PMs e o Exército, por meio do questionamento das noções difundidas pela história oficial da PMERJ, de que sua origem histórica ocorreu em 1809 (MELO; REIS; MONTEIRO, 1925), e da PMESP (ARRUDA, 1997), segundo a qual sua origem oficial deu-se em 1831, e o senso comum de que as Polícias Militares são instituições criadas durante o período da Ditadura Militar no Brasil (IHU on line, 2014). Buscou-se demonstrar o processo histórico de formação dessas instituições, suas imbricações com a história do Exército e as permanências e mudanças ao longo dos anos.

O estudo das PMs torna-se relevante na atualidade em razão da necessidade de que as corporações militares passem por alterações em seus padrões culturais, com o objetivo de modificar comportamentos e evitar desvios de conduta contrários ao respeito à democracia e aos Direitos Humanos (DH). Essa temática tem-se tornado tão importante que diversos pesquisadores e ativistas ligados aos DH passaram a ter, por objeto, o estudo das PMs, como é o caso do ativista Jair Krischke (IHU On-Line, 2014), e de diversos intelectuais envolvidos com o Fórum Brasileiro de Segurança Pública², entre outros.

Sob o espectro historiográfico, a produção científica a respeito da história das corporações policiais no Brasil tem apresentado um crescimento importante. Bretas e Rosemberg (2013) realizaram uma pesquisa sobre essa produção e identificaram tendências. Apontaram uma predominância das chamadas histórias oficiais até os anos de 1960, produzidas "em sua maioria por antigos policiais" (p. 163). Dentre essas produções é possível citar as obras de Silveira (1955) e Malvásio (1967). Na década de 1970, a academia tendia a analisar as instituições policiais sob a perspectiva de esquemas explicativos. O liberal relacionava as instituições policiais como integrantes do "progresso moderno" (BRETAS; ROSEMBERG, 2013, p. 163). O marxista analisava essas corporações como "parte do arsenal repressivo, agindo sob as ordens de um

1 Nomenclatura da instituição responsável pela atividade de policiamento no Estado de São Paulo até 1970, quando seu nome foi alterado para PMESP.

2 Dentre os intelectuais ligados ao Fórum Brasileiro de Segurança Pública que estudaram as PMs podemos destacar Barros (2009), Ribeiro e Montandon (2015), Silva e Gurgel (2016), entre outros. 
Estado ou de uma burguesia opressora" (idem). Período de importantes produções sobre a PMESP, como as obras de Fernandes (1977) e Dallari (1977).

Já em meados dos anos de 1980, chegaram novas propostas teóricas, como as ideias de Thompson (1981), que criticam os grandes esquemas explicativos e promovem uma renovação na historiografia brasileira perceptível até os dias atuais. Essa renovação trouxe novos objetos e revelou:

a precariedade do conhecimento que se tinha - ainda se tem - da Polícia, tanto em sua organização formal, os códigos legais que a regiam e que comportavam enormes variações regionais que só desapareceriam a partir da década de 1930, quanto nas práticas cotidianas, mais ou menos relacionadas com esses códigos legais. (BRETAS; ROSEMBERG, 2013, p. 166).

Bretas e Rosemberg sugerem ainda que, nessa nova fase, apareceram estudos de caráter regional e cronológico. A abordagem cronológica "nos faz pensar como a ideia e a prática de policiamento vão experimentando diferentes sentidos ao longo dos séculos" (2013, p. 166). Os estudos regionais reconhecem as "inúmeras diferenças históricas, geográficas e culturais que constituem o chamado Brasil" (idem). No conjunto dessa nova produção, merecem destaque obras como a de Holloway (1997), Bretas (1997, 1998), Cotta (2014), entre outras. O levantamento aponta ainda para novas análises, como

as oscilações históricas brasileiras entre o reforço do poder local ou do poder central [que] produziram uma variação nos organismos policiais; momentos de maior centralização tenderam à uniformização dos aparatos policiais, enquanto momentos de descentralização permitiram maior autonomia na constituição destes organismos. (BRETAS; ROSEMBERG, 2013, p. 166-167).

Exatamente nessa vertente é que podemos incluir as investigações propostas por este artigo. A análise da oscilação entre o fortalecimento do poder local e a centralização não é um estudo novo, obras com as de Carvalho (2001) demonstram como em determinados momentos as forças militares estaduais foram utilizadas como instrumentos de fortalecimento das forças políticas locais. Talvez a maior contribuição deste trabalho seja exatamente demonstrar como os próprios integrantes das forças militares estaduais agiram para assegurar seus próprios interesses no "movimento [...], em direção à uniformidade que se inicia nos anos 1930" (BRETAS; ROSEMBERG, 2013, p. 167). O que demonstra parcela da dinâmica interna dessas organizações e como essa dinâmica influenciou até mesmo a organização constitucional de todo o aparato de segurança pública no Brasil presente até os dias atuais.

Para atingir esses objetivos, estudamos o processo de criação de dois modelos de PM no Brasil até a década de 1930: a Polícia Militar do Distrito Federal (PMDF)³ e a FPESP. Nesse sentido, utilizamos as ideias de Thompson sobre a interpretação da história como processo (THOMPSON, 1981, p. 58). A partir dessa noção, definimos que a história das PMs não é resultado de supostos "momentos de criação", mas é fruto de todo um processo que apresenta momentos de mudanças e permanências.

Seguindo as orientações de Thompson (1981, p. 53-54), que considera que a produção historiográfica não pertence apenas à esfera das abstrações, estando ligada também à comprovação empírica por meio do uso de fontes, os procedimentos metodológicos usaram a ideia de que os conceitos e as evidências devem "conversar" entre si, por meio de comparações que busquem comprovar a aplicabilidade de determinado

3 Denominação dada à PMERJ entre 1920 e a fundação de Brasília em 1961. 
conceito em determinado quadro empírico. Para tal, foram pesquisados diversos tipos de fontes, buscando compreender os fatos importantes para o processo. Tal procedimento abrange fontes primárias - como documentos, legislações e periódicos - e fontes secundárias - como produções historiográficas, que auxiliaram na compreensão do contexto do período analisado.

Por tratar-se de um estudo que versa sobre o processo histórico de invenção de toda uma cultura institucional, o que pode ser enquadrado dentro do "imenso domínio cultural" definido por Braudel (1965, p. 269), foi necessário definir os marcos históricos que assinalaram os momentos marcantes da história dessas instituições. Por isso, o recorte temporal engloba a fundação da Divisão Militar da Guarda Real de Polícia da Corte do Rio de Janeiro (DMGRP), em 1809, até a regulamentação das PMs em 1936.

A partir da pesquisa sobre a história da PMDF e da FPESP, foi possível perceber uma série de momentos de ruptura na história dessas corporações, incluindo as imbricações que deram origem ao padrão legal de PM disseminado em todo o Brasil durante a Era Vargas.

\section{O CORPO MILITAR DE POLÍCIA DO MUNICÍPIO NEUTRO (1809-1889)}

Em 1808, o processo de adaptação das instituições policiais de Lisboa para a cidade do Rio de Janeiro se iniciou com o decreto de criação da Intendência Geral de Polícia da Corte e do Estado do Brasil (IGPC) (BRASIL, 1808). Já em 1809, foi criada a DMGRP (BRASIL, 1809). Anexo a esse último decreto, foi publicado o regulamento da nova corporação. Nessa norma podemos destacar: a dupla subordinação do comandante da corporação à IGPC e ao governador das Armas da Corte; que os integrantes da corporação seriam os "melhores soldados [...] da guarnição desta Corte"; e a sujeição deles ao Conselho de Guerra e ao rigor das leis militares (BRASIL, 1809). 0 que evidencia a criação de uma organização militarizada que exercia as funções de policiamento.

Em 1831, com a abdicação de D. Pedro I, o grupo de liberais que assumiu a regência reorganizou as forças do Império. Primeiramente foi publicada a lei que extinguiu o Corpo da Guarda Militar de Polícia do Rio de Janeiro (BRASIL, 1831a). Em agosto, foi criada a Guarda Nacional (GN) (BRASIL, 1831b) e publicada a lei que fixava as forças de terra ordinária para o ano financeiro de 1831-1832, que extinguiu todos Corpos da Guarda Militar de Polícia (BRASIL, 1831c). Em outubro, as províncias foram autorizadas a criar suas próprias Guardas Municipais Permanentes (BRASIL, 1831d). Nessa organização percebemos a descentralização das atribuições policiais e o enfraquecimento do Exército.

Em 1841 foi promovida nova reorganização das forças de segurança brasileiras por meio de uma reforma no Código de Processo Criminal (BRASIL, 1841), que criou a figura do chefe de Polícia na Corte e nas províncias. Essa lei foi regulada em 1842, trazendo de volta a centralização das forças de segurança (BRASIL, 1842a). O Corpo de Guardas Municipais Permanentes do Rio de Janeiro também foi afetado por essa reforma por meio de um novo regulamento, que definiu que a hierarquia, a disciplina e a organização da corporação voltariam a ser semelhantes às do Exército (BRASIL, 1842b). Isso marca um movimento de centralização e a retomada da influência do Exército na estruturação do sistema de segurança brasileiro.

Durante o Segundo Reinado, o Corpo de Guardas Municipais Permanentes da Corte sofreu diversas alterações. Nesse período, a instituição foi organizada como: Corpo Policial da Corte (BRASIL, 1858), Corpo Militar de Polícia da Corte (BRASIL, 1866) e Corpo Militar de Polícia do Município Neutro (BRASIL, 
1889a). O regulamento de 1889 foi a última alteração antes da proclamação da República, sendo também uma das primeiras normas que prevê a condição de uma força policial ser auxiliar do Exército durante operações militares (BRASIL, 1889a, art. $3^{\circ}$ ).

\section{A POLIICIA MILITAR DO DISTRITO FEDERAL}

Em 1889 foi proclamada a República e, em 1891, foi promulgada a primeira Constituição republicana do Brasil (BRASIL, 1891). No que se refere à organização do Estado, na nova forma de governo, os parlamentares deliberaram que cada uma das antigas províncias do Império formaria um Estado e o antigo Município Neutro seria reestruturado para a criação do Distrito Federal - DF (BRASIL, 1891). Assim, o antigo Corpo Militar de Polícia do Município Neutro foi reorganizado, dando origem ao Regimento Policial da Capital Federal (BRASIL, 1890a), posteriormente à Brigada Policial da Capital Federal (BRASIL, 1890b). Essa organização policial manteve as características de ser uma instituição policial, militarizada e auxiliar do Exército.

No final do séc. XIX e início do XX, diversos incidentes evidenciaram o despreparo e o atraso do Exército. As difíceis vitórias nos conflitos de Canudos (1896-1897) e do Contestado (1912-1916) demonstraram o despreparo das tropas e a falta de efetivos. Tanto no conflito de Canudos quanto na Guerra do Contestado, tropas do Exército atuaram em conjunto com forças militares estaduais, o que demonstrou uma nova fonte de efetivos: transformar as forças militares estaduais em reservas, como havia ocorrido com o Corpo Militar de Polícia do Município Neutro em abril de 1889 (BRASIL, 1889a). Segundo o decreto de remodelação do Exército de 1915, suas forças compreenderiam "o conjunto de homens armados, instruídos, organizados e mantidos pela Nação, para sua defesa" (BRASIL, 1915, art. 10). A lei que fixava "as forças de terra para o exercício de 1917" (BRASIL, 1917) definiu que a Brigada Policial do Distrito Federal, o Corpo de Bombeiros da Capital e as Polícias Militarizadas dos Estados, cujos presidentes estivessem de acordo, passariam a constituir forças auxiliares do Exército.

Por fim, no ano de 1920, a Brigada Policial do Distrito Federal sofreu uma nova remodelação, dando origem à primeira PM do Brasil: a PMDF. O regulamento de 1920 da PMDF (BRASIL, 1920) previa que a corporação seria subordinada ao ministro da Justiça, devendo estar à disposição das autoridades policiais no DF. Essa norma também definiu que a nova corporação seria força auxiliar do Exército. A hierarquia na PMDF deveria seguir o padrão do Exército Brasileiro (EB), com os postos mais elevados da instituição ocupados por oficiais do Exército. Nessa norma também foi organizado um sistema próprio de formação dos oficiais da PMDF denominado Curso Profissionalizante.

\section{O EXÉRCITO PAULISTA}

A substituição das províncias pelos Estados, decorrente da proclamação da República, fortaleceu a proposta do federalismo, como se pode depreender do art. 65 da Constituição de 1891, a seguir: "É facultado aos Estados [...] em geral, todo e qualquer poder ou direito, que thes não for negado por cláusula expressa ou implicitamente contida nas cláusulas expressas da Constituição" (BRASIL, 1891). Isso reforçou uma ideia de "estadualização" presente no ideário dos políticos dos Estados mais poderosos, como São Paulo.

Por outro lado, durante o governo de Floriano Peixoto (1891-1894), o Exército tornou-se um risco a esse federalismo. Assim sendo, o governo de São Paulo passou a se preocupar em formar forças militares 
capazes de garantir a autonomia conseguida com a Constituição de 1891. Tal postura era assegurada pelo disposto no art. $8^{\circ}$ do decreto que oficializou a proclamação da República, que previa a existência de uma força pública regular, constituída pelas Forças Armadas, mas possibilitava que os Estados organizassem guardas cívicas destinadas ao policiamento (BRASIL, 1889b). Assim, em novembro de 1891, foi criada a FPESP por meio da unificação de todos os Corpos Policiais do Estado. Uma corporação militarizada, com efetivo de 3.940 homens, que seria controlada pelos políticos paulistas (SÃO PAULO, 1891).

Amaral (1966) observa que os governadores paulistas, especialmente Campos Sales, buscaram maneiras de garantir a estabilidade por meio de medidas como a criação e ampliação de uma força militar estadual. Prova dessa tese está em uma correspondência "reservada" entre Campos Sales e Bernardino de Campos, datada de 1902, como segue:

V. é governo; não assombre-se com os boatos e procure tornar simpática a República. Uma preocupação V. deve tomar, eu já aconselho para São Paulo desde o Governo de Prudente, é que deve ser muito bem organizada e disciplinada a nossa força policial, dando o comando a homens de confiança. Com 5 mil homens (que é o efetivo segundo creio), V. pode conservar um grosso de 2 mil permanentes na Capital. Esta gente, sob um regime rigorosamente militar, será o casco poderoso para qualquer eventualidade. (AMARAL, 1966, p. 33).

Seguindo essa proposta, o governo paulista aumentou o efetivo da FPESP e os investimentos com material bélico, instalações e profissionalização. Em 1906, buscando essa profissionalização, foi contratada uma missão militar francesa (MMF) para auxiliar na instrução da tropa. Com essa medida, o governo de São Paulo foi pioneiro na contratação de uma missão militar estrangeira para a organização do sistema de ensino de sua força ${ }^{4}$, incluindo a organização de um curso militar para a formação dos oficiais da corporação.

O receio de uma intervenção militar manifestado pelos presidentes de São Paulo nos primeiros anos do período republicano veio a confirmar-se durante o governo de Hermes da Fonseca. O historiador Paulo Schmidt estudou a "Política das Salvações" e constatou que "em 1911 o governo [federal] tentou intervir em São Paulo, mas o governador Albuquerque Lins mobilizou a Força Pública [...] neutralizando a ameaça" (SCHMIDT, 2016, p. 90). Nesse evento, percebemos que a proposta de manter a FPESP pronta para atuar como "casco poderoso para qualquer eventualidade" (AMARAL, 1966, p. 33), manifestada por Campos Sales em 1902, se demonstrou útil aos interesses políticos da oligarquia paulista. Assim, a FPESP, paulatinamente, foi se transformando no pequeno Exército paulista descrito por Dalmo Dallari (1977), até a Revolução de 1930, quando o fim da política dos governadores e a centralização do poder puseram em risco a própria existência da corporação.

\section{A DISSEMINAÇÃO DO MODELO DE POLÍCIA MILITAR}

Desde 1809, a história das PMs tem como uma de suas questões o dilema entre a subordinação das forças de segurança pública militarizadas ao Exército, ou às forças políticas regionais. Podemos destacar dois momentos definidores desse embate: a descentralização do período regencial, marcada pela desarticulação do Exército com a criação das Guardas Municipais Permanentes; e o retrocesso conservador

4 Cabe destacar que outras corporações militares estaduais também contrataram militares estrangeiros para promoverem o aprimoramento militar de suas tropas, como é o caso da Força Pública de Minas Gerais, que contratou o capitão Roberto Drexler, do exército suiço (COTTA, 2014, p. 131). 
da década de 1840, que impôs às mesmas corporações a vinculação ao poder central e voltou a fortalecer o Exército. Essa análise esclarece o temor que perdurou durante décadas no ideário de diversos oficiais do EB, de que as forças militares estaduais fossem utilizadas em movimentos que ameaçariam a unidade nacional e, por consequência, o próprio Exército. Tanto que diversos militares discutiram o assunto, como é o caso de alguns dos editores e articulistas da revista A Defesa Nacional (ADN) 5 .

Após a Revolução de 1930 e o fim da Política dos Governadores, as forças militares estaduais demonstraramse uma ameaça para o governo recém instalado. Nesse sentido, militares ligados à revista ADN passaram a publicar editoriais e artigos sobre a questão. Na edição 206 (ADN, 1931a), encontramos o editorial Polícias militarizadas, que discute a ameaça à unidade nacional representada pela existência de pequenos Exércitos estaduais. Esse texto concluiu que essas forças estaduais militarizadas deveriam ser extintas ou subordinarem-se ao Exército. A primeira tentativa de controle das forças militares estaduais foi a promulgação do Código dos Interventores (BRASIL, 1931), que diminuía o poder dos governos estaduais, limitava os gastos com as chamadas PMs, proibia a essas corporações a posse de peças de artilharia e aviões de combate, e limitava a quantidade de armas automáticas e de munição.

Logo após a promulgação do Código dos Interventores, foi publicada a edição 213 da revista ADN (1931b), que traz o editorial Polícias Militares, onde são debatidas as funções das PMs e a vinculação que essas forças deveriam ter em relação ao Exército. Em junho de 1932, na edição 222 da revista, o major J. B. Magalhães publicou o artigo A propósito da federalização das polícias (MAGALHÃES, 1932), que explica a ameaça separatista representada pela existência de forças militares estaduais e os inconvenientes para o próprio EB, e para os Estados, caso esssas corporações fossem extintas. Para o autor, a possibilidade de se agrupar essas forças militares em uma gendarmerie nacional traria um aumento de custos para o governo federal. Finalizando o artigo, propõe que as forças militares estaduais devam ser mantidas pelos Estados, mas controladas pelo Estado Maior do Exército (EME).

A solução proposta já havia sido encontrada em 1920: o modelo da PMDF. Dessa forma, foi desenvolvido um projeto no qual as forças militares estaduais deveriam ser transformadas em corporações semelhantes à PMDF. Esse processo passou pela consolidação das PMs na Constituição de 1934 e pela regulamentação dessas corporações por meio de uma lei em 1936.

\section{A CONSTITUIÇÃO DE 1934}

Os trabalhos da Assembleia Nacional Constituinte iniciaram-se em novembro de 1933 e terminaram em julho de 1934, quando foi promulgada a nova Constituição. Durante esse período, foram publicadas na revista ADN novas propostas com relação às forças militares estaduais, como o artigo do Ten. Cel. da reserva Torres Guimarães intitulado Legião Federal de Carabineiros (GUIMARÃES, 1933). Nesse trabalho é proposta a unificação das forças militares estaduais em uma única corporação, a Legião Federal de Carabineiros, que, em tempos de paz, executaria os serviços normais das PMs e, em caso de guerra, seria mobilizada como reserva do Exército. O custeio do efetivo dessa corporação seria encargo do Ministério da Guerra, que obteria os recursos por meio de repasses dos governos estaduais. Essa proposta reforça a questão do controle das forças militares estaduais pelo Ministério da Guerra, mas

5 Alguns dos oficiais do EB, que tinham estagiado na Alemanha e outros entusiastas, fundaram, em 1913, a revista A Defesa Nacional. Tratase de um periódico publicado até os dias atuais, que se constitui um meio de divulgação das ideias de reforma e modernização do Exército e outros assuntos considerados de interesse estratégico por seus editores. 
gera um problema quanto aos recursos para manutenção dos serviços policiais: como se daria o repasse de verbas para custear a corporação?

Soma-se às propostas da revista ADN a posição do general Góes Monteiro, que, em janeiro de 1934, foi nomeado ministro da Guerra. Bretas observou que em um relatório encaminhado à Getúlio Vargas antes de assumir o cargo de ministro da Guerra, Góes Monteiro manifestou sua preocupação com diversas questões. Nesse documento foi proposto que as polícias estaduais deveriam ser subordinadas ao EME (BRETAS, 2008, p. 57-59).

Nesse contexto, a corrente da federalização das forças militares estaduais ganhou maior força, inclusive com a participação de políticos ligados ao Exército atuando junto à Assembleia Constituinte. Podemos destacar a atuação do deputado Odon Pereira de Cavalcanti na defesa dos interesses do Exército na questão das PMs, como é possível se depreender das preposições nos 467 e 468 elaboradas por ele. A preposição n 467 previa que as PMs seriam forças reservas e auxiliares do Exército (BRASIL, 1937, p. 77-78). Para que essa proposta fosse implementada, seria necessário que as PMs tivessem uma instrução militar mínima, como foi sugerido na preposição nº 468, que também recomendava a padronização da formação dos quadros das PMs a partir do padrão do Exército.

Por outro lado, as próprias PMs articularam-se por meio de parlamentares para defenderem seus interesses. Podemos destacar a atuação do deputado Campos do Amaral, que elaborou a proposição $n^{\circ}$ 1.392, que defendia a continuidade das forças militares estaduais como PMs, "forças auxiliares do Exército de $1^{\mathrm{a}}$ linha", mantendo as garantias, honras e os proventos previstos para as demais forças armadas (BRASIL, 1937, p. 150-151). A justificativa faz alusão a dois casos de extinção de forças militares estaduais: a extinção da Força Pública do Estado do Mato Grosso, logo após a Revolução de 1932, e da Força Pública do Estado do Pará em 1930.

O caso da Força Pública do Estado do Pará era um argumento emblemático para a manutenção das forças militares estaduais em evitar a substituição delas por guardas civis ${ }^{6}$. Rego (1981) confirma que a Força Pública do Estado do Pará foi extinta logo após a Revolução de 1930, quando o interventor Joaquim de Magalhães Cardoso Barata assumiu a chefia do executivo do Estado. Essa extinção foi uma retaliação aos integrantes da corporação em razão da forte repressão ao movimento tenentista na década de 1920. A corporação foi substituída por uma Guarda Civil que, em 1932, entrou em greve. O que fez o próprio interventor, que havia extinguido a corporação, convocar seus reservistas e criar a Polícia Militar do Estado do Pará. Esse evento reforçou o argumento de que substituir uma corporação militar por uma civil poderia acarretar problemas de indisciplina, como a greve da Guarda Civil do Pará de 1932.

Além de Campos do Amaral, as forças militares estaduais contaram com o apoio de outros deputados, como Arruda Câmara. Os parlamentares da base de apoio das PMs emitiram o parecer nº 639, o qual propunha a seguinte redação para a constitucionalização das PMs:

Artigo. As Polícias Militares são consideradas forças auxiliares do Exército de primeira linha e gozarão das mesmas vantagens atribuídas ao Exército quando a ele incorporadas ou quando a serviço da União.

Parágrafo. A lei ordinária federal regulará a sua organização, instrução, garantias, estabilidade e justiça. (BRASIL, 1937, p. 93-94).

6 O estudo histórico indica que outras corporações militares estaduais enfrentaram o Exército Brasileiro, como o caso da Força Pública de Minas Gerais durante a Revolução de 1930 (COTTA, 2014, p. 146-149). 
Na justificativa desse parecer foi destacada a participação dos integrantes das PMs nas atividades policiais, na manutenção da ordem, no combate ao banditismo e na defesa da Pátria quando incorporadas ao Exército.

O processo parlamentar resultou no art. 167 da Constituição de 1934, como segue: "art. 167 - As polícias militares são consideradas reservas do Exército, e gozarão das mesmas vantagens a este atribuídas, quando mobilizadas ou a serviço da União" (BRASIL, 1934). Assim, o texto final da Constituição de 1934 definiu a questão das PMs, optando pela corrente de editores da revista ADN e dos militares estaduais que defendiam a sua federalização como força reserva e auxiliar do Exército. Um modelo de instituição semelhante à PMDF.

\section{A LEI DE ORGANIZAÇÃO DAS POLÍCIAS MILITARES (1936)}

Antes mesmo da promulgação da nova Constituição, em maio de 1934, na edição 242 da revista ADN, o cap. A. da Silva Chaves publicou o artigo O problema das polícias (CHAVES, 1934). Esse artigo anunciou os avanços na questão das PMs na Assembleia Nacional Constituinte de 1933 e, na sequência, propôs uma lei federal para regulamentação dessas corporações como organizações policiais dos Estados e fonte de reservistas para o Exército. Segundo o texto, a lei proposta deveria discorrer sobre diversas questões como efetivo, comando, formação de oficiais, entre outras. Merece destaque a sugestão de que o comando das PMs deveria ser uma atribuição de um oficial superior do Exército (CHAVES, 1934, p. 355), e que os demais oficiais dessas corporações deveriam ser oficiais da reserva formados pelo Centros Preparatórios do Exército (idem, p. 356). Essa proposta desarticulava os sistemas existentes em algumas PMs que já possuíam seus próprios cursos de formação de oficiais, como nos casos da FPESP e da PMDF.

Continuando o processo, em julho de 1935, o presidente Getúlio Vargas encaminhou ao Congresso o anteprojeto de lei elaborado pelo EME que regulamentaria a situação das PMs (BRASIL, 1935a). Nesse anteprojeto de lei, constatamos uma tentativa de regulamentar as PMs limitada à questão de transformálas em reserva do EB, algo muito semelhante à Lei nº 3.216/17 (BRASIL, 1917).

As forças militares estaduais, agora transformadas em PMs, articularam-se novamente e enviaram oficiais para "instruírem" os deputados da base de apoio das corporações. Integraram a equipe que "instruiu" o deputado Arruda Câmara, o capitão da FPESP Manoel da Rocha Marques e o capitão da PMDF Teófilo Peres Barbosa (A FORÇA POLICIAL, 2005, p. 1-4). Por conta desse embate político, o projeto de lei de regulamentação das PMs teve diversas emendas e dois substitutivos, merecendo destaque a discussão sobre a obrigatoriedade do comandante de uma PM ser um oficial do EB, tal como era proposto pelo regulamento de 1920 para a PMDF; e a tese de se aplicar nas PMs os regulamentos e as instruções do EB, no que se refere à instrução militar, e, quanto às instruções policiais, utilizar as instruções da PMDF (BRASIL, 1935b).

Depois de diversas discussões parlamentares foi promulgada a Lei $n^{\circ}$ 192/36. Essa norma definiu que competiam às PMs as funções de vigilância e garantia da ordem, garantia do cumprimento da lei, segurança das instituições, exercício dos poderes constituídos e, nos casos de guerra externa, atender à convocação do governo federal (BRASIL, 1936, art. 2º).

Quanto à composição e à organização, as PMs seriam compostas por voluntários, com organização, equipamento e armamento adequados à atividade policial (BRASIL, 1936, art. $3^{\circ}$ ), sendo que o efetivo e o 
armamento das unidades das PMs não poderiam exceder os do Exército em tempo de paz (BRASIL, 1936, art. $4^{\circ}$ ). Ainda, o art. 12 trazia explicitamente a proibição às PMs de possuírem peças de artilharia, aviões e carros de combate, com exceção de pequenos carros blindados. Observa-se, assim, que essa organização previa o controle do efetivo e do arsenal das PMs, como defendiam diversos articuladores da revista ADN e o Código dos Interventores de 1931 (BRASIL, 1931).

Quanto à cultura militar que deveria predominar nas PMs, o Exército impôs o seu padrão, iniciando pela nomenclatura dos postos e das graduações, com destaque para o fato de que as PMs não poderiam ter o posto de general, que era de exclusividade das Forças Armadas (BRASIL, 1936, art. 5º. Por sua vez, o comando das PMs caberia aos oficiais do Exército ou aos oficiais das próprias corporações, sendo que o oficial do Exército nomeado comandante de uma PM seria comissionado no maior posto da instituição (BRASIL, 1936, art. 6º). Além disso, os integrantes das PMs estariam sujeitos ao Código Penal Militar e teriam foro especial para o julgamento dos delitos. Para tanto, cada Estado deveria criar a sua justiça militar (BRASIL, 1936, art. 19). Por fim, seriam adaptados às PMs os regulamentos e as instruções do Exército (BRASIL, 1936, art. 22) e os sistemas de instrução dos quadros de tropa seriam obrigatoriamente dirigidos por oficiais do EB, postos à disposição dos governadores dos Estados e nomeados pelo EME (BRASIL, 1936, art. 26).

Nesse dispositivo legal percebemos a criação de um forte mecanismo de controle das PMs por parte do EME, o que passa pelo controle do efetivo e do arsenal das corporações. Além disso, o Exército definiu o padrão cultural a ser adotado na formação dos quadros dessas organizações: o próprio padrão cultural do Exército. Isso foi garantido pelo controle que o EME estabeleceu sobre os sistemas de formação dos integrantes das PMs. Essa norma marca um momento de mudanças e a criação do modelo de PM que será disseminado por todo o Brasil durante a Era Vargas.

\section{CONCLUSÕES}

O presente artigo demonstrou a alternância entre fases de maior centralização e controle das forças policiais por parte do Exército e períodos de maior autonomia delas. São marcos dessas mudanças a criação da DMGRP em 1809, a descentralização de 1831, a nova centralização da década de 1840 e a promulgação da constituição de 1891, com a possibilidade de que os Estados pudessem ter forças militarizadas. Nesse embate ocorreram disputas entre segmentos dos oficiais do Exército e forças políticas estaduais no controle das corporações responsáveis pela atividade de policiamento.

Nas primeiras décadas do sec. XX, o próprio Exército enfrentou problemas com seus efetivos durante os conflitos de Canudos e do Contestado. Assim, o comando do Exército entendeu ser necessário ampliar seus efetivos, com isso surgiram as ideias de forças reservas em 1915 (BRASIL, 1915), polícias militarizadas em 1917 (BRASIL, 1917) e, por fim, em 1920, a antiga DMGRP, à época Brigada Policial do Distrito Federal, transformada na PMDF (BRASIL, 1920). Essa foi a primeira organização policial militar da República com as características de ser força auxiliar do EB, o que, na época, implicava controle da corporação por meio da nomeação de oficiais do Exército como instrutores e comandantes.

Enquanto isso, na década de 1890, o governo de São Paulo aglutinou todos os Corpos de Polícia do Estado criando a FPESP. Corporação militarizada que executava o serviço de policiamento, a repressão às manifestações populares e passou a ter a função de defesa territorial do Estado contra ameaças 
externas. Ao longo dos primeiros anos do século XX, a FPESP foi transformada em um pequeno Exército que defendia os interesses da oligarquia paulista. Esse processo se deu por meio da ampliação de seus efetivos, compra de material bélico e contratação de missões francesas de instrução militar.

A partir de fontes como a revista ADN, foi detectado que alguns oficiais do Exército consideravam que a existência de forças militares estaduais representava uma ameaça para a unidade nacional. Nesse sentido surge um grupo de militares que defendia a transformação dessas forças em PMs, forças auxiliares do Exército. Tal medida seria um mecanismo de manutenção dessas corporações, executando o serviço de policiamento, sendo custeadas pelos governos estaduais, mas controladas pelo EME. Com isso, os militares assumiriam o controle de grande parcela das forças policiais no Brasil. O modelo para essa mudança já existia, a PMDF, que exercia a atividade de policiamento, com a instrução e o comando da corporação sendo controlados por oficiais do Exército.

Esse projeto passou pela constitucionalização das PMs em 1934 (BRASIL, 1934), e pela sua regulamentação em 1936 (BRASIL, 1936). O estudo dos processos legislativos que geraram essas normas trouxe à tona a disputa que envolveu o tema, inclusive relativizando a força do projeto do próprio EME quanto ao controle das PMs. Enquanto o grupo favorável à transformação das forças militares estaduais em PMs articulou-se junto ao Poder Legislativo, integrantes das próprias corporações estaduais atuaram politicamente na defesa de seus interesses. Nesse embate, as normas relativas às PMs, especialmente o regulamento de 1936, foram mais favoráveis às corporações estaduais do que os projetos originais encaminhados pelo EME.

A atuação conjunta de oficiais da FPESP e da PMDF, nas articulações políticas durante a elaboração do regulamento das PMs de 1936, mostra que grupos de oficiais dessas corporações trabalharam para construir um novo modelo de instituição. Percebe-se claramente que a proposta de se transformar em uma PM seria mais relevante para a sociedade, o que garantiria a sobrevivência das corporações, visto que a condição de pequeno Exército estadual era cara e, para a população, pouco útil. A única utilidade real de um pequeno Exército estadual seria a defesa dos interesses dos próprios governadores, o que colocava as PMs à mercê do jogo político de um grupo que havia perdido o poder em 1930. Com a transformação em PMs, os militares estaduais ganhariam o próprio Exército como uma espécie de chefe e aliado contra a extinção das corporações, e passariam a ter o monopólio sobre um serviço de maior relevância social, o policiamento.

Esses fatos põem em discussão a versão oficial de que as PMs brasileiras tiveram suas origens no séc. XIX ${ }^{7}$ ou a versão de que são fruto da reorganização do Estado brasileiro durante a Ditadura Militar (19641985). Essas corporações não podem ser interpretadas como estátuas que permanecem imutáveis após sua criação, sendo alteradas apenas a partir de sua destruição e reaproveitamento da matéria-prima que restou. Não, essas organizações são compostas por atores que se adaptam às novas realidades, o que marca um conjunto de permanências e mudanças na organização e na cultura das instituições. Até mesmo a cultura militar dessas corporações sofreu alterações com o passar do tempo.

Neste ponto foi possível perceber que uma das características mais importantes dessas instituições é a sua capacidade de assimilação e acomodação, evitando a extinção total, adaptando-se às imposições, reorganizando-se e sobrevivendo às mudanças. Como uma Fênix, que busca forças no próprio conflito que a destrói, para ressurgir das próprias cinzas. Um ser novo que, ao menos na aparência, mantém elementos do antigo, vivendo em permanente mudança na busca da sua própria conservação.

7 Outros pesquisadores também criticam essa história "oficial", como Bretas (2013) e Cotta (2014). 


\section{REFERÊNCIAS BIBLIOGRÁFICAS}

A DEFESA NACIONAL. Polícias militarizadas. A Defesa Nacional, revista de assuntos militares, ano XVII, v. 18, ก. 206, p. 1-2, fev. 1931a.

Polícias militares. A Defesa Nacional, revista de assuntos militares, ano XVII, v. 18, n. 213, p. 1-2, set. $1931 \mathrm{~b}$.

A FORÇA POLICIAL. Manoel da Rocha Marques. A Força Policial, revista de assuntos técnicos da polícia militar, São Paulo, n. 45, p. 1-4, jan./Fev./mar. 2005.

AMARAL, Antonio Barreto do. A missão francesa de instrução da Força Pública de São Paulo (1906-1914). Revista do Arquivo Municipal, São Paulo, n. CLXXII, 1966.

ARRUDA, Luiz Eduardo Pesce de. Polícia Militar: uma crônica. A Força Policial, revista de assuntos técnicos da polícia militar, São Paulo, n. 13, p. 31-84, jan./fev./mar. 1997.

BARROS, Lúcio Alves de. O paisano, a política e a "comunidade": a polícia na encruzilhada. Revista Brasileira de Segurança Pública, São Paulo, v. 3, n. 2, p. 160-184, ago./set. 2009. Disponível em: <http:// revista.forumseguranca.org.br/index.php/rbsp/article/view/58>. Acesso em: 21 mar. 2017.

BRASIL. Alvará de 10 de maio de 1808. Cria o lugar de Intendente Geral da Polícia da Corte e do Estado do Brasil. Coleção de Leis do Império do Brasil, Rio de Janeiro, 1808, p. 26.

Decreto de 13 de maio de 1809. Cria a divisão militar da Guarda Real da Polícia no Rio de Janeiro. Coleção de Leis do Império do Brasil, Rio de Janeiro, 1809, p. 54.

Constituição Política do Império do Brasil: promulgada em 25 de março de 1824. Brasília, DF: Presidência da República. Disponível em: <http://www.planalto.gov.br/ccivil_03/Constituicao/ Constituicao24.htm>. Acesso em: 20 maio 2020.

Lei de 17 de julho de 1831. Extingue o Corpo da Guarda Militar de Polícia do Rio de Janeiro. Coleção de Leis do Império do Brasil, Rio de Janeiro, Parte I, 1831a, p. 22-23.

. Lei de 18 de agosto de 1831. Cria as Guardas Nacionais e extingue os corpos de milícias, guardas municipais e ordenanças. Coleção de Leis do Império do Brasil, Rio de Janeiro, Parte I, 1831b, p. 49-75.

Lei de 30 de agosto de 1831. Fixa as forças de terra ordinária para o ano financeiro de 1831-1832. Coleção de Leis do Império do Brasil, Rio de Janeiro, Parte I, 1831c, p. 83-86.

Lei de 10 de outubro de 1831. Autoriza a criação de corpos de guardas municipais voluntários nesta cidade e províncias. Coleção de Leis do Império do Brasil, Rio de Janeiro, Parte I, 1831d, p. 129-131.

. Decreto $n^{\circ}$ 30, de 22 de fevereiro de 1839. Dando nova organização ao Exército do Brasil. Coleção de Leis do Império do Brasil, Rio de Janeiro, v. 1, Parte I, 1839, p. 32.

. Lei n²61, de 3 de dezembro de 1841. Reforma o Código do Processo Criminal. Coleção de Leis do Império do Brasil, Rio de Janeiro, Tomo IV, Parte I, 1841, p. 101- 122.

Regulamento $n^{\circ}$ 120, de 31 de janeiro de 1842. Regula a execução da parte policial e criminal da Lei n² 261, de 3 de dezembro de 1841. Coleção de Leis do Império do Brasil, Rio de Janeiro, Tomo V, Parte II, 1842a, p. 39-135.

Decreto $n^{\circ} 191$, de $1^{\circ}$ de julho de 1842 . Regula a organização e disciplina da Guarda Municipal Permanente. Coleção de Leis do Império do Brasil, Rio de Janeiro, Tomo V, Parte II, 1842b, p. 353-376. 
Decreto $n^{\circ} \mathbf{2 . 0 8 1}$, de 16 de janeiro de 1858. Regula a organização e disciplina do Corpo policial da Corte. Coleção de Leis do Império do Brasil, Rio de Janeiro, Tomo XIX, Parte II, 1858, p. 26-45.

Decreto $n^{\circ}$ 3.598, de 27 de janeiro de 1866. Reorganiza a força policial da Corte, dividindo-a em dois Corpos, um militar e outro civil. Coleção de Leis do Império do Brasil, Rio de Janeiro, Tomo XXIX, Parte II, 1866, p. 45-55.

Decreto n 10.222, de 5 de abril de 1889. Dá novo Regulamento para o Corpo Militar de Polícia da Corte. Coleção de Leis do Império do Brasil, Rio de Janeiro, Tomo L, Parte II, 1889a, p. 399-471.

Decreto $n^{\circ}$ 1, de 15 de novembro de 1889. Proclama provisoriamente e decreta como forma de governo da Nação Brasileira a República Federativa, e estabelece as normas pelas quais se devem reger os Estados Federais. Diário Oficial da União, Rio de Janeiro, 16 nov. 1889b. Disponível em: <http://legis. senado.leg.br/norma/385329/publicacao/15772955>. Acesso em: 19. ago. 2018.

Decreto $n^{\circ}$ 155, de 14 de janeiro de 1890. Altera a organização da força policial da Capital Federal. Decretos do Governo Provisório da República dos Estados Unidos do Brasil, Rio de Janeiro, v. 1, 1890a, p. 48-49.

Decreto $n^{\circ}$ 852, de 13 de outubro de 1890. Eleva a brigada o Regimento Policial da Capital Federal. Decretos do Governo Provisório da República dos Estados Unidos do Brasil, Rio de Janeiro, v. 10, 1890b, p. 2.803.

Constituição (1891). Constituição da República dos Estados Unidos do Brasil. Diário Oficial da União, de 24 de fevereiro de 1891. Rio de Janeiro: Imprensa Nacional, 1891. Disponível em: <http://www. planalto.gov.br/ccivil_03/constituicao/Constituicao91.htm>. Acesso em: 14 ago. 2019.

Decreto n 11.497, de 23 de fevereiro de 1915. Faz a remodelação do Exército Nacional. Diário Oficial da União, Seção 1, 28 fev. 1915, p. 2.275. Disponível em: <https://www2.camara.leg.br/legin/fed/ decret/1910-1919/decreto-11497-23-fevereiro-1915-513642-publicacaooriginal-1-pe.html>. Acesso em: 14 ago. 2019.

Lei $\mathbf{n}^{\circ} \mathbf{3 . 2 1 6}$, de 3 de janeiro de 1917. Fixa as forças de terra para o exercício de 1917. Diário Oficial da União, Seção 1, 4 jan. 1917, p. 89. Disponível em: <https://www2.camara.leg.br/legin/fed/lei/19101919/lei-3216-3-janeiro-1917-572527-publicacaooriginal-95671-pl.html>. Acesso em: 14 ago. 2019.

Decreto n 14.508, de 1 de dezembro de 1920. Aprova o regulamento para a Polícia Militar do Distrito Federal. Coleção de Leis da República dos Estados Unidos do Brasil, Rio de Janeiro, v. III, 1920, p. 959-1205. Disponível em: <https://www2.camara.leg.br/legin/fed/decret/1920-1929/decreto-14508-1dezembro-1920-504302-norma-pe.html>. Acesso em: 15 ago. 2019.

Decreto $n^{\circ}$ 20.348, de 29 de agosto de 1931. Institui conselhos consultivos nos Estados, no Distrito Federal e nos municípios e estabelece normas, sobre a administração local. Diário Oficial da União, Rio de Janeiro, Seção 1, 23 out. 1931, p. 16.835. Disponível em: <https://www2.camara.leg.br/legin/fed/ decret/1930-1939/decreto-20348-29-agosto-1931-517916-publicacaooriginal-1-pe.html>. Acesso em: 14 ago. 2019.

Constituição (1934). Constituição da República dos Estados Unidos do Brasil, de 16 de julho 1934. Diário Oficial da União, Rio de Janeiro, 16 jul. 1934. Disponível em: <http://www.planalto.gov.br/ccivil_03/ constituicao/Constituicao34.htm>. Acesso em: 14 ago. 2019.

Diário do Poder Legislativo. Rio de Janeiro, 21 jul. 1935a, p. 2.474-2475. 
Diário do Poder Legislativo. Rio de Janeiro, 29 dez. 1935b, p. 10.161-10.170.

Lei $n^{\circ}$ 192, de 17 de janeiro de 1936. Reorganiza, pelos Estados e pela União, as Polícias Militares sendo consideradas reservas do Exército. Diário Oficial da União, Seção 1, 22 jan. 1936, p. 1716. Disponível em: <https://www2.camara.leg.br/legin/fed/lei/1930-1939/lei-192-17-janeiro-1936-501765publicacaooriginal-1-pl.html>. Acesso em: 14 ago. 2019.

Anais da Assembleia Nacional Constituinte. Rio de Janeiro: Imprensa Nacional, v. 19, 1937.

BRAUDEL, Fernand. História e Ciências Sociais: a longa duração. Revista de História, São Paulo, v. 30, n. 62, p. 261-294, jun. 1965. Disponível em: <http://www.revistas.usp.br/revhistoria/article/ view/123422/119736>. Acesso em: 30 abr. 2017.

BRETAS, Marcos Luiz. Polícia e Polícia Política no Rio de Janeiro dos anos 1920. Revista do Arquivo Público do Estado do Rio de Janeiro, Rio de Janeiro, v. 3, p. 25-34, 1997.

. A Polícia Carioca no Império. Revista de Estudos Históricos, Rio de Janeiro, v. 12, n. 22, p. 219234, 1998.

. O general Góis Monteiro: a formulação de um projeto para o Exército. Militares e Política, Rio de Janeiro, v. 2, p. 31-61, 2008.

:i ROSEMBERG, André. A história da polícia no Brasil: balanço e perspectivas. TOPOI, v. 14, p. 162173, 2013.

CHAVES, A. da Silva. O problema das polícias. A Defesa Nacional, ano XXI, n. 242, p. 351-357, maio 1934.

CARVALHO, Glauco S. Forças públicas: instrumento de defesa da autonomia estadual e de sustentação da política dos governadores na Primeira República (1889-1930). Dissertação (Mestrado em Ciência Política) - Faculdade de Filosofia, Letras e Ciências Humanas, Universidade de São Paulo - FFLCH/USP, São Paulo, 2001.

COTTA, Francis A. Breve História da Polícia Militar de Minas Gerais. 2. ed. v. 1. Belo Horizonte: Fino Traço, 2014.

DALLARI, Dalmo A. O pequeno exército paulista. 2. ed. São Paulo: Perspectiva, 1977.

FERNANDES, Heloisa R. A Força Pública do Estado de São Paulo. In: FAUSTO, Boris. História geral da civilização brasileira. v. 3, tomo II, Rio de Janeiro: Difel, 1977, p. 258-280.

GUIMARÃES, Torres. Legião Federal de Carabineiros. A Defesa Nacional, ano XX, n. 235, p. 478-479, out. 1933.

HOLLOWAY, Thomas. Polícia no Rio de Janeiro. Repressão e resistência numa cidade do século XIX. Rio de Janeiro: FGV, 1997.

IHU On-Line. A Polícia Militar é uma invenção da ditadura. Entrevista especial com Jair Krischke. IHU OnLine, São Leopoldo, 16 jun. 2014. Disponível em: <www.ihu.unisinos.br/entrevistas/532364-a-ditadurafez-com-que-perdessemos-mais-de-uma-geracao-de-politicos-entrevista-especial-com-jair-krischke>. Acesso em: 10 out. 2018.

MAGALHÃES, J. B. A propósito da federalização das polícias. A Defesa Nacional, ano XVIII, n. 222, p. 291292, jun. 1932.

MALVÁSIO, Luiz Sebastião. Anais históricos da Força Pública. São Paulo: Força Pública do Estado de São Paulo, 1967. 
MELO, Gustavo Moncorvo Bandeira; REIS, Carlos da Silva; MONTEIRO, Albino. História da Polícia Militar do Distrito Federal: desde a época da sua fundação. Rio de Janeiro: Tipografia da Polícia Militar, 1925.

REGO, Orlando L. M. de Moraes. Retrospectivo Histórico da Polícia Militar do Estado do Pará 18221930. Belém: Falangola Off Set, 1981.

RIBEIRO, Ludmila Mendonça Lopes; MONTANDON, Ana Maria Alemão. Reformar a polícia ou reformar o seu discurso? Uma análise da chegada da filosofia de policiamento comunitário a uma organização policial militar brasileira. Revista Brasileira de Segurança Pública, São Paulo, v. 9, n. 1, p. 62-81, fev./mar. 2015. Disponivel em: <http://revista.forumseguranca.org.br/index.php/rbsp/article/view/442>. Acesso em: 14 abr. 2017.

SÃO PAULO (Estado). Lei n 17, de 14 de novembro de 1891. Fixa a Força Pública do Estado para o ano de 1892. Diário Oficial do Estado, São Paulo, SP, 1891. Disponível em: <https://www.al.sp.gov.br/repositorio/ legislacao/lei/1891/lei-17-14.11.1891.html>. Acesso em: 20 nov. 2010.

SCHMIDT, Paulo. Guia politicamente incorreto dos presidentes da República. São Paulo: LeYa, 2016.

SILVA, Gabriela Galiza; GURGEL, Yara Maria Pereira. A polícia na Constituição Federal de 1988: apontamentos sobre a manutenção de um órgão militarizado de policiamento e a sua incompatibilidade com a ordem democrática vigente no Brasil. Revista Brasileira de Segurança Pública, São Paulo, v. 10, n. 1, p. 142-158, fev./mar. 2016. Disponível em: <http://revista.forumseguranca.org.br/index.php/rbsp/article/view/597>. Acesso em: 22 fev. 2017.

SILVEIRA, Geraldo Tito. A Polícia Militar de Minas. Belo Horizonte: Imprensa Oficial, 1955.

THOMPSON, Edward Palmer. A miséria da teoria ou um planetário de erros. Uma crítica ao pensamento de Althusser. Rio de Janeiro: Zahar, 1981. 


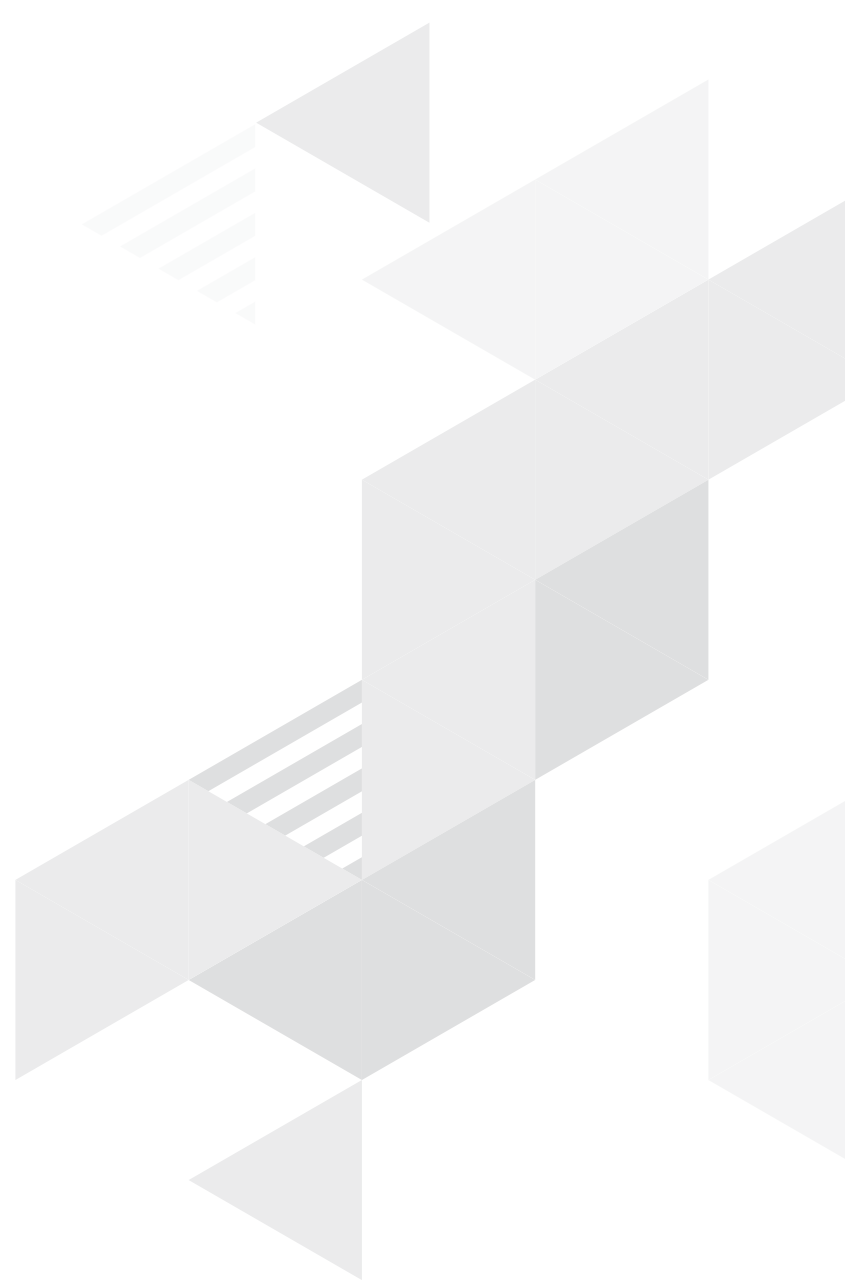

